\title{
E-Learning Systems Rendering Trustability
}

\author{
Amit Kumar Bajpai \\ Research Scholar \\ Amity University, Lucknow
}

\author{
Rajiv Pandey, PhD \\ Amity University \\ Lucknow Campus, Lucknow
}

\begin{abstract}
The World Wide Web is perhaps the most transformative technology which is reshaping business, media, entertainment, and society in many ways. But for all its power, it is just now being tapped to transform education. The web is the enabler to e-Learning, wherein the learners are linked to virtual campuses extracting their knowledge based information from any corner of the World. Rather than fetching the ambiguous data from repository, it is required, that the data be trustable and semantically valid. The growing need for communication, visualization and organization technologies in the field of elearning environments has led to the demand of semantically structured and trustable information. In an efficient functioning of any e-Learning system, the data provenance aspect has to be very closely integrated during the development phase.
\end{abstract}

\section{Keywords}

e-Learning System, e-content, Provenance, Ontology.

\section{INTRODUCTION}

The objective of this paper is to address the up-rising and pervasive needs originating for the effective and efficient distribution of electronically published content available online, this content is personalized and is available on demand and the most important feature is that it is available on $24 \times 7 \times 365$ basis, life-long learning and knowledge transfer experiences through the Web are the key features of such a learning experience which can be called as eLearning. In this context the web or internet is a main source that facilitates the transfer of electronic contents on the click of a button.

This paper presents an approach of semantic and provenance embedded e-learning system. Any web engineered e-Learning systems using the state-of-art technologies and software agents can be very useful in rendering trustabilty and semantically structured resource.

\section{WEB ENGINEERING IN NUTSHELL}

The Web is the best-known example of a hypermedia system. To date, numerous organizations worldwide have developed a vast array of commercial and/or educational Web applications. The Web literature uses numerous synonyms for a Web application, such as Web site, Web system.

Web site defined as [1]:

"A collection of logically connected Web pages managed as a single entity."

With reference to the above definition we would like to understand that the e-Learning system would be a "collection of logically connected electronic contents documents related to a particular topic and managed as a single entity."

To date the development of a e-Learning Web applications has been in general ad hoc, resulting in poor-quality application which are difficult to maintain. The main reasons for such problems are unsuitable design and development processes, and poor project management practices.

Thereby to make a e-Learning Web application more demanding and knowledge dissipating calls for the software engineering aspect to be embedded in e-Learning System solution. Thereby web engineering has to be carried out.

Web engineering is described as [2]:

"the use of scientific, engineering, and management principles and systematic approaches with the aim of successfully developing, deploying and maintaining high quality Web-based systems and applications."

\section{INTRODUCTION TO E-LEARNING SYSTEM}

E-Learning education is just beginning, with something of far greater promise. Yet technology, even in its current stage of development, can already allow us to realistically dream of achieving the under mentioned

- To center learning around the student instead of the classroom

- To focus on the strengths and needs of individual learners

- To make lifelong learning a reality

The above mentioned goals have only been achieved because the technology or the web help us to overcome the barriers which were prominent in the early years The promise of the web based e learning system cannot be realized till these barriers are overcome. Distinct barriers to web-based education which are being overcome are as follows:

- Greater access to broadband connectivity

- Guidance in the best uses of the Web for learning

- Understanding of how people learn differently with the Internet

- Content that leverages the powerful capabilities of the Web

While addressing the web engineering needs of a e-Learning system we have to begin with a fundamental process of communication to understand how learning takes place only then we can transform it to an effective e-Learning system.

There is no such thing as a comprehensive communication model. If you would look in any communication textbook you would be confronted with many alternatives. Most are a series of ovals connected by arrows that show how the communication process is supposed to work. Although there are reasons for each model, they share common elements. 
The three major elements are:

- Message

- Channel

- Receiver

The two minor elements are:

- Interference

- Feedback

In all communication models a message is communicated to a receiver through a channel. If the message received resembles the message sent, then effective communication has taken place.

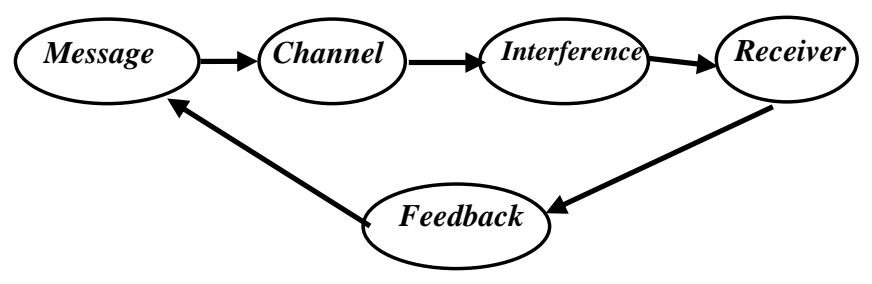

Fig 1: Communication process

\section{UNDERSTANDING A LEARNING ENVIRONMENT}

Most training has been conducted the same way since the dawning of time: a 'master' imparts information to a 'novice'. The only thing that has changed is the method of delivery. In the 1950's, a new training approach moved the emphasis of training from 'content-centered' to 'learner-centered' education. 'Content-centered' learning is mainly concerned with the presentation of information; whereas 'learnercentered' training environments focus upon communicating the information to the learner.

The 'learner-centered' approach does more than simply present information. It is designed to make sure that learners understand as well as receive the information communicated to them.

\section{LEARNING PROCESS TRANSFORMED INTO E-LEARNING (LEARNER-CENTRIC)}

The figure-1 is transformed with the Learner-centric approach as the base of an e-Learning system. The e-content repository serves as the main source of knowledge which provides the desired knowledge based contents to the learner as and when he demands.

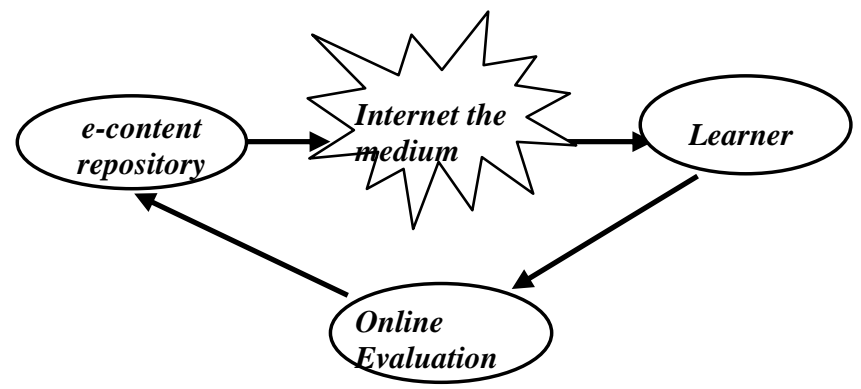

Fig 2: e-Learner Communication Process

In an e-Learning environment, the main difference is the channel and the instructional methods chosen. The 'dynamic teacher' of the classroom is replaced with media elements.
The media elements, with their characteristics, production values and method of delivery, must now convey the instructional message with incorporating the evaluation based feedback at frequent interval. The problem that occurs with many e-Learning pieces is the inability to translate the instructional message into the correct media components (the design feature of web engineering). When media is used in place of the 'instructor', it must fulfill two roles: the role of the channel and the role of instructional methods. Therefore, the third step in effective e-Learning is to know how to use media to communicate.

\section{THE MEDIA TO BE WEB- ENGINEERED}

The e-Learning system is the content provider to the learner World-wide. Thus the user variety, taste with respect to look and feel changes drastically. Therefore the media/web has to be engineer to satisfied the needs of multiple learners. Some aspects of Web-engineering applied to e-Learning system can be viewed as below:

1. The look and feel (GUI) or the layout considerations take the highest priority. Which is influence by the design aspect of any Web application? To cater for multiple audience World-wide the requirement engineering from large distributed learners has to be the prime focus. The layout considerations should ensure unity and harmony across the presentation of the learning system [8]. The established screen partition into three horizontal functional parts (identification area, learning area and control area) described by Strzebkowsky [3] and shown in Figure 3 are served as a basis for the design consideration.

\begin{tabular}{|l|}
\hline Identification area \\
\hline \\
Learning area \\
\hline Control area \\
\hline
\end{tabular}

Fig 3: The established learning interface [3]

\section{Navigation across the e-book}

The organization of e-content has to be in a orderly manner so that the navigation is simplified for the learner. This also ensures that the learners interest is held through out the learning process.

Navigation refers to finding the relevant information in the learning system. The interaction by the learner is primarily controlled by the need/demand that is perceived by the learner. Researchers have described the continuous access to nodes and the information selection as the major components of the learning process. He distinguishes between the following types of information access:

- Search (entering a search word or a combination of search words causes a system feedback if there are matches in the relevant nodes or not),

- Navigation (strongly connected with providing of associated links, which increase the linearity of the information system - the more navigation options, the more linear becomes the original structure), 
- Browsing (includes an explorative information search, which can be designed more or less goal oriented).

The main user strategies for navigation that improve the learner's comprehension and enhance the learner's motivation can be summarized as follows:

- $\quad$ Glossary (aid to search for unknown terms),

- Graphical illustrations of relationships between important ideas and / or terms,

- Access to linked nodes containing important information,

- Permanent display of the current location in the learning space,

- Access to nodes with alternative presentation of the node content,

- Bookmark management

- Use of focus mode (supporting the learner in solving navigation and orientation problems and facilitating the context abstraction process).

3. The Appropriate Technology for the delivery of econtent at a optimal speed (keeping the learner end factors as constant) to be achieved so that the learner remains engrossed with the contents that he received and the factor of lethargy and fatigue do not creep in, and the learner terminates the learning process. This aspect of technology selection demands economical and technical feasibility study which is the prime factor of any web engineered application.

4. The updation of e-content (as per figure-4) should be carried out at a regular frequency to keep pace with the changing demands of the learner. This will ensure that the learner is delivered only that which he needs. Therefore a continuous maintenance aspect of the econtent repository has to be incorporated.

It is prominent from the above study that e-learning system have to be web-engineered to deliver the e-content with the following attributes, it should

- Be delivered at the desired time.

- Be delivered in the desired quantity.

- $\quad$ Be delivered in the desired knowledge base.

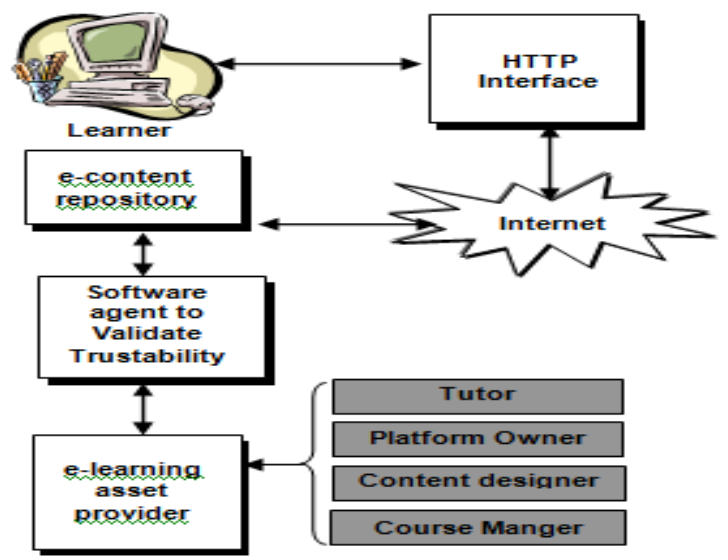

Fig 4: Proposed e-learning system rendering trustability
The above e-learning system can be supported by the various tools [12] which can be classified under two major categories:

1. Learner tools include:

- Web browsing - multimedia, security, etc.

- Asynchronous sharing - email, newsgroup, file exchange, etc.

- Synchronous sharing - audio/video chat, whiteboard, virtual space, teleconferencing, etc.

- Student tools - progress tracking, searching, motivation building, etc.

2. Support tools include:

- Course - planning, managing, customizing, monitoring, etc.

- Course contents - instructional designing, presenting information, testing, etc.

- Data - marking on-line, managing records, analyzing and tracking, etc.

- Resource - curriculum managing, building knowledge, team building, etc.

- Administration - installation, authorization, registering, server security, etc.

- Help desk - student support, instructor support.

Figure-4 is the design view of a e-learning system which shall satisfy learner demands in context of knowledge based satisfaction and operational satisfaction. The learner using his machines shall interact with the HTTP interface that may be provided and shall request for information as per his need. The request of the learner via the web shall be routed to an econtent repository. This repository shall serve the information to the learner.

The e-content repository can be an information bank which may be housing e-contents provided by various e-learning asset providers. These asset providers in turn shall accumulate the contents which may be provided by the following:

- Tutor: Tutor is the owner of the course and subcategories of courses. A tutor can organize and structure the session, drop learners from a session, mute them, give the floor to others.

- Platform owner: Platform owner (short name: Sys Admin) has all rights and can modify everything, gives the role of user manager and course manager to a member.

- Content designer: The content designer is also the layout manager who shall ensure the contents are placed in a orderly manner in reference to (figure3).

- Course-manager: The courses manager can maintain the courses structure of a provider organization.

\section{TRUSTABILITY: ENHANCING BELIEF}

Trustability or trust worthiness of information rendered by any e-learning framework is a major concern, providing a clear trust model without the ambiguity of the information being fetched and consumed enhances the comprehension of the learner, researcher, and developers. Further the scope will 
remain towards development of such model in which we structure the digital objects with the semantic and provenance Meta data, such that the machine returns the semantic results as well as trustable information. The provenance of the data calls for a restructuring of the existing e-learning web resources into a format that is both understandable by man and machine .Such semantically structured OWL/RDF documents are called as ontology.

"A specification of a conceptualization of a specific domain" [15]

We need to make ontology such that it can incorporate provenance metadata to render authentic results. It is important to be able to transfer trust between the parts on the semantic web. However a user seeking information will need to judge whether the content of any given source is in fact trustworthy. It is therefore, important to develop said model along with trust in the context of e-learning and semantic web.

Fig. 4 therefore incorporates a component in terms of software agent that is customized to validate all the ontologies for their provenance prior to being populated in the e-learning repository. The detailed description of the provenance validation is beyond the scope of this paper. However it is stated that Provenance can be incorporated using $\mathrm{PROV}=\mathrm{O}[14]$ nomenclature specified by W3C .PROV-O nomenclature a XML and RDF serialized thus can be interpreted by any browser and enable efficient learning without downloading any ADD-ins.

A semantic e-Learning can be summed up as follows:

1. Follow sound instructional design, make sure the instructional message is clear and the information well organized.

2. Know your learners, what are their strengths and weaknesses. Know their background so that you can build on their previous knowledge.

3. Effectively use media elements to convey the instructional message. The media used must also be appropriate for the learner and the instructional message being communicated.

4. The e-learning model which will have its data semantically structured (OWL ontology) and most importantly it will incorporate Provenance through PROV-O will be trust able for end user.

The quality of 'good' e-Learning is one in which the intended instructional message is understood by the learner. 'Bad' eLearning is one where the instructional message is present but gets lost in the media clutter. When you run across an eLearning piece that simply lacks any discernable instructional message, that e-Learning is just plain 'ugly.'

\section{CONCLUSION}

This paper outlines the need of Web-engineering at various phases of a e-learning system along with trustability aspect as well as the data would be semantically structured. If all the aspects of Web-engineering system are incorporated during the development of e-learning system that ensures PROV and semanticisation of all web repositories then a good e-learning system is generated which meets all the needs of a learner. Apart from the some bottle necks i.e. internet band width, elearning infrastructure and across the web collection of ontologies of various domains. The semantic e-learning system shall address the needs of large learners. With the advancement of technology many new tools and equipments are available which can facilitate e-Learning without the apprehension of authenticity of delivered resources.

\section{REFERENCES}

[1] IEEE Std. 2001-2002 (2003) Recommended Practice for the Internet Web Site Engineering, Web Site Management, and Web Site Life Cycle, IEEE.

[2] Murugesan S, Deshpande Y (2001) Web Engineering, Managing Diversity and Complexity of Web Application Development, Lecture Notes in Computer Science 2016, Springer Verlag, Heidelberg.

[3] Brusilovsky, P., Karagiannidis, C., \& Sampson, D. (2002).A Case for Layered Evaluation of Adaptive Applications and Services.

[4] Cardinali, F., DaBormida, G., Vaccaro, R., Grosso F., \& Sampson, D. (2001). The KOD (Knowledge-onDemand) Packaging Toolkit: an XML adaptive learning content management system. Paper presented at the European Multimedia, Embedded Systems and Electronic Commerce Conference, October 17-19, 2001, Venice, Italy.

[5] Karagiannidis, C., \& Sampson, D. (2002).Re-using Adaptation Logics for Personalised Access to Educational e-Content.In Proceedings of the Workshop on Adaptive Systems for Web-Based Education.2nd International Conference on Adaptive Hypermedia and Adaptive Web-Based Systems.Malaga, Spain, May 28, 2002.

[6] Stary, J. (1997). Visualization in study and practice.

[7] Jackson, B. (1999). Review of leading asynchronous, web based course delivery tools,

[8] Klett F. \& Schade H.-P. (2001). Hypermedia - The Unity of Instruction and Design. In Frindte, W. \& Koehler, T. (Eds.) Internet and Communication, Vol. 3. Frankfurt: Peter Lang.

[9] Kloss, J. \& Rockwell, R. \& Szabo, K. \& Duchrow, M. (1998). VRML97 Der neue Standard für interaktive 3Dwelten in World Wide Web. Bonn: Addison-WesleyLongman.

[10] Strzebkowski, R. (1997). Information and Learning in Multimedia

[11] Schulmeister, R. (1997). Hypermedia Learning System: [Theory and Design].

[12] Jackson, B. (1999). Review of leading asynchronous, web based course delivery tools,

[13] James Hendler. Tetherless world Chair ACM 978-14503-0148-/05, Semantic web 10th year update.

[14] WWW.W3.ORG/TR/POV-primer, PROV model Primer W3C Working Note 30 April 2013.

[15] T. R. Gruber, "towards principle for the design of ontologies used for knowledge sharing", International journal of human and computer studies, Vol.43,1995. 